\title{
Algunas consideraciones sobre la lealtad de Ceuta a la Corona Hispánica en 1640
}

\author{
Josefina Castilla Soto *
}

Resulta verdaderamente curioso plantearse las causas que llevaron a los naturales de Ceuta a permanecer fieles a la Corona Hispánica en 1640 cuando se produjo el levantamiento de Portugal. Para llegar a ellas es ineludible observar la trayectoria seguida por este presidio del Norte de África en las centurias inmediatamente anteriores.

La conquista portuguesa de Ceuta se produjo en agosto de 1415 durante el reinado de Juan I de Portugal. Para ello se empleó una numerosa tropa encabezada por los infantes don Pedro y don Enrique, con gran concurrencia de la nobleza lusitana ${ }^{1}$.

Portugal vio en la conquista de Ceuta la oportunidad de iniciar desde ella el comercio con África, beneficiándose de los productos supuestamente autóctonos: cereales, pesca, ganado..., pero también, el modo de cerrar la expansión castellana en la zona ${ }^{2}$. El carácter de las ciudades costeras norteafricanas como centros exportadores de trigo, fue algo muy

* Profesora de Historia Moderna. UNED.

1 "Las armas propias de esta ciudad son las mismas que las del Reino de Portugal, que sus primitivos Reyes le señalaron, o por ser ésta la primera conquista de su Corona, o porque determinaron hacerla cabeza y metrópoli del Imperio que desearon constituir en África, dependiente del Reino Lusitano" (MASCARenHAS, J. de, Historia de la ciudad de Ceuta: sus sucesos militares y políticos, memorias de sus santos y prelados y elogios de sus capitanes generales, escrita en 1648. Lisboa 1918).

2 SAnz SAMPElayo, J., "Los presidios españoles del Norte de África y su aprovisionamiento de viveres a fines del siglo XVIli», Anuario de Historia Moderna y Contemporánea, núms. 4-5, 1977-78, pág. 101. 
importante en los objetivos de la colonización portuguesa, ya que Ceuta podía solucionar el déficit crónico de cereales padecido por la metrópoli ${ }^{3}$.

Así, la ciudad pasó a convertirse en presidio y guarnición, impidiéndose casi todo tipo de manifestaciones al margen de las estrictamente militares. Sin embargo, con el paso del tiempo, el enclave fue asemejándose cada vez más a una población del litoral meridional español en la que no faltaban las fiestas religiosas y civiles ${ }^{4}$. A esta paulatina, pero constante «españolización» del presidio, clave de su lealtad en 1640, contribuyó de forma importante el frecuente envío a Ceuta de fuerzas castellanas que colaboraban en la defensa de la plaza, permanentemente amenazada por los naturales de las zonas fronterizas ${ }^{5}$. Verdaderamente, resultaban más cercanos y fáciles de enviar, así como menos costosos, los refuerzos castellanos que los portugueses.

El mismo Felipe II, antes de convertirse en soberano portugués, había venido ofreciendo ayuda a los ceutíes en su constante lucha contra los mogrebinos del Norte de África, lo que contribuyó a crear un ambiente previo de simpatía hacia los Austrias, en la figura del Rey castellano, por parte de la plaza africana ${ }^{6}$.

Conviene tener en cuenta que la población musulmana huyó tras la conquista de la plaza por Portugal, pero siempre permaneció en la espera y confianza de que la ocupación sería temporal. Además eran bastante frecuentes las correrías y escaramuzas entre los ceutíes y los moros al salir aquéllos de sus lindes en busca de forrajes y leña?

Más grave aun que el ataque de sus vecinos resultaba el de las potencias internacionales, en particular, se temió por la beligerancia de-

3 LuXÁn MELÉndez, S. de, «Contribución al estudio de los presidios españoles del Norte de África: las dificultades de la plaza de Ceuta para abastecerse de trigo (1640-1668)", Hispania, núm. 130, 1975, pág. 322.

4 Gordillo Osuna, M., Geografía Urbana de Ceuta. Madrid 1972, pág. 177.

${ }_{5}$ "Ceuta 11 de diciembre. El sitio de esta Plaza se mantiene con tanto empeño que ya tienen los moros sus ataques a prueba de cañón en la misma punta de la lengua de sierpe (estrada encubierta nuestra) y desde ella hasta otro ataque cortando el Pozo de Chafariz, distante de San Pedro tiro de pistola y desde la esquina de la franqueza nueva que está la misma distancia de la Plaza de Armas, cortan otro ataque hasta la estrada encubierta de Santa Ana, ...estamos esperando los mil hombres Infantes portugueses y 500 de Extremadura porque parece habrá de llegarse a las manos muy brevemente. Las galeras están en Gibraltar no habiéndoles permitido el tiempo pasar a esta plaza» (Biblioteca Nacional de Madrid (en adelante BNM), MSS 18755, exp. 25. Ceuta atacada por los moros, s.f.).

- Martín GutiérRez, D. J., “Aspectos histórico-jurídicos sobre la incorporación de Ceuta a la Corona de Castilla", C.A.M.C., II/5, 1989, pág. 82.

7 Correa da Franca, A., Historia de Ceuta en BNM, Mss. 9745, fol. 1084. 
sencadenada por Carlos Estuardo en 1625, razón por la cual se enviaron amplios refuerzos a Ceuta. A ello se sumaban las incursiones de los navíos extranjeros con el objeto de vender armas a los moros que restaban en las plazas o presidios hispanos en el Norte de África. Así, se comunicó por medio del Gobernador de Orán, maqués de Flores Dávila, la llegada de un navío inglés con armas y municiones para distribuir en las plazas, contando con la connivencia de un rico judío ceutí ${ }^{8}$, 10 cual, al parecer, se producía con una cierta frecuencia.

En 1640 tuvo lugar el levantamiento de Portugal. Este Reino había conservado desde su anexión en 1580, bajo el reinado de Felipe II, sus propias instituciones lo que le había permitido desarrollarse como una nación casi independiente que contaba además, con un importante imperio ultramarino del que obtenía grandes ventajas económicas. Olivares, mediante su conocido proyecto de la "Unión de Armas" se había propuesto una "castellanización» de la Península en toda su extensión, lo cual se traducía en una mayor presión fiscal.

Las continuas peticiones tanto tributarias como militares de Olivares ${ }^{9}$ fueron respondidas con sucesivos levantamientos en Oporto (1628), Santarém (1629) y Évora (1637).

Por otra parte, las clases altas portuguesas, que en 1580 habían apoyado la candidatura de Felipe II al trono portugués esperando obtener importantes beneficios comerciales de la unión con el imperio colonial hispano, se encontraban ahora desengañadas al contemplar cómo los enemigos de España atacaban sus posesiones coloniales. Además, cada vez era menor el caudal de plata americana que llegaba a Sevilla, al

${ }^{8}$ Biblioteca Real Acadenia de la Historia (en adelante BRAH), Colección Salazar y Castro, K-16 (9/641), fol. 84. (Carta de Felipe IV al marqués de Flores Dávila, de 30 de octubre de 1633).

9 «Sácanse de aquel Reino de Portugal para Castilla mucha suma de ducados y fuera, de muchos millones que montan donativos, impuestos, derechos de Casa de India y Alfandega, medias anatas y otros servicios; se sacan también las rentas que están situadas para una armada que ande por todas aquellas costas y le alargue a los mares y esto por asiento de los mercaderes que voluntarios impusieron sobre sus haciendas un tanto para este efecto; sácase también lo situado para cuatro galeras que eran el remedio de las costas y que con ellas se alargaban los pescadores a entrar más en el mar y los moros no se atrevian a andar como andan agora que llegan a vista de Lisboa y todo esto que pudiera ser alivio de aquel Reino y terror de los enemigos, ven que lo pagan, que lo padecen y ello se desperdicia porque dicen ( $y$ esto muy en público así en esta Corte como en Lisboa) que el retiro lo consume todo y embravecen los ánimos cuando discurren que lo que pudiera ser honra y provecho, injustamente se defrauda a los pretextos con que se concibieron los tales impuestos..." (BNM, Mss. 2370, fols. 360 v y 361 r. Memorial que se dio a Su Magestad en el año de 1639, anónimo). 
tiempo que las autoridades en América osaban restringir las actividades de los comerciantes portugueses.

La conjura nobiliaria se hizo patente en Portugal alrededor del duque de Braganza, descendiente directo de uno de los que fueron contrincantes de Felipe II en 1580 cuando se produjo la anexión de Portugal. El Conde-Duque intentó en repetidas ocasiones sacar al duque de Braganza de Portugal, mediante el ofrecimiento del virreinato de Milán o del desempeño de algún cargo importante en la Corte, pero con resultados adversos.

Los acontecimientos que se habían iniciado en Cataluña impulsaron a los conjurados a comenzar las hostilidades. Aprovechando la circunstancia de que las fuerzas militares castellanas se estaban empleando en el frente catalán, los portugueses se levantaron en armas y proclamaron al duque de Braganza rey de Portugal, con el nombre de Juan IV. Era el 1 de diciembre de 1640. Las Cortes portuguesas, integradas por los tres brazos, reconocieron a Juan IV como legítimo soberano, al igual que todos los gobernadores de los territorios ultramarinos a excepción de Ceuta ${ }^{10}$.

A fines de 1640 llegaron noticias a la plaza sobre los últimos acontecimientos acaecidos en Portugal. Al frente de los destinos ceutíes figuraban como principales personajes ${ }^{11}$ :

- Gobernador de Ceuta: don Francisco de Almeida, caballero de probado valor $y$ experiencia adquirida en la guerra de África y como almirante de la Armada; había sido nombrado para el cargo a comienzos de octubre de 1637.

- Visitador: don Bernardo Sampayo de Morais, nombrado durante el gobierno de Almeida para inspeccionar los organismos locales, en los que observó ciertas irregularidades. rado.

- Contador Juez de la Real Hacienda: don Gonzalo Correa Alcofo-

10 ... «la única plaza de la Corona de Portugal en las cuatro partes del orbe, en que el Rey nuestro señor, conserva y continúa la posesión de Rey de aquel Reino, que defiende el que ocupa su gobierno mientras duran las turbaciones presentes" (MASCARENHAS, J. de, op. cit., pág. 16).

11 BNM, Mss. 9741, fols. 110 r a 111 v. (CORREA da Franca, A., op. cit.). Nos ofrece una lista completa de los personajes que ocupaban los principales cargos en Ceuta en 1640. 


\section{Franca.}

- Escribano de las Cuentas y Aduana: don Simón de Andrade de

Al margen de la clase dirigente integrada en la pequeña nobleza, la ciudad de Ceuta, muy poco poblada por otra parte, contaba con la presencia de soldados y pequeños comerciantes, pueblo menudo y gran cantidad de esclavos. La mayor parte de esta población era de estirpe lusitana, mientras que los hispanos residentes en Ceuta eran, en su gran mayoría, soldados procedentes de Andalucía.

Ante la noticia de los acontecimientos que se desarrollaban en Portugal, la nobleza ceutí acordó mantenerse fiel a Felipe IV y así se lo comunicó al gobernador Francisco de Almeida quien «respondió floja y ambiguamente» ${ }^{12}$. El pueblo apoyó esta resolución y se unió a la nobleza en sus aclamaciones hacia Felipe IV.

En realidad, la decisión de los ceutíes no entrañaba un cambio de nacionalidad, pero consideraban que la legitimidad regia correspondía exclusivamente al monarca de la Casa de Austria ${ }^{13}$. Por ello desde Ceuta se reclamó la presencia del corregidor de Gilbraltar para que tomase a sus naturales juramento de fidelidad a la Corona de Castilla.

El 5 de febrero de 1641, don Juan Fernández de Córdoba, marqués de Miranda de Anta y caballero del hábito de Santiago, era nombrado nuevo gobernador de Ceuta, siendo el primer castellano que ostentaba dicho cargo.

El cesado Francisco de Almeida regresaba a la Corte obedeciendo órdenes de Madrid, al tiempo que se le dictaba un juicio de residencia respecto a su labor gubernativa en Ceuta.

El 14 de febrero se concedía el perdón general a los moradores de la plaza norteafricana:

«Yo el Rey hago saber a los que este edicto vieren que la ciudad de Ceuta me ha pedido que en consideración de la fidelidad y lealtad con que siempre han procedido los caballeros y moradores derramando su sangre y empleando sus vidas en mi servicio, mandara usar con ellos de mi Real clemencia concediéndoles perdón general de todas las culpas por las cuales está procediendo contra ellos el juez Bernardo de Sampayo de Morais y que fuesen sueltos libremente sin pagar nada y que así se procediese con los castellanos que están presos por orden

12 Ibidem., fol. 112 r.

13 Posac Mon, C., La última década lusitana de Ceuta. Ceuta 1967, pág. 18. 
del Gobernador don Francisco de Almeida y teniendo yo consideración y deseando hacerles la merced que por su lealtad merecen, tengo por bien y me place de conceder perdón general a los moradores de ella y que no se proceda contra ninguno de ellos ahora ni en tiempo alguno porque así es mi voluntad y también quiero y mando que se suelten los presos y los castellanos por lo que mando a todos los ministros y oficiales que tengan conocimiento de éste, que lo cumplan y hagan cumplir sin duda, ni embargo, ni dilación alguna porque así lo tengo por mi servicio y este edicto valdrá, puesto que no ha pasado por la Cancillería y que su efecto tenga que durar más de un año a pesar de la disposición del libro segundo, títulos 39 y 40 que dispone lo contrario, el cual se registrará en el libro de las cuentas de la dicha ciudad" ${ }^{14}$.

Con ello Ceuta recibía el título de Noble y Leal.

Desde Madrid se adoptaron medidas prioritarias para normalizar la vida política ceutí, manteniendo las coordenadas preexistentes antes de la revolución y solucionar la crisis económica. En este sentido, el Gobernador, marqués de Miranda de Anta, escribió una carta el 13 de noviembre de 1641 dando cuenta de la miserable situación del Ejército apostado en Ceuta debido al retraso de las pagas durante el último trienio y a la carencia de ropas. De esa situación se desprendía un manifiesto descontento por parte de la soldadesca ${ }^{15}$.

El Rey, mediante carta de 27 de enero de 1642, se comprometió a solucionar la situación. Así, se dispuso el envío de soldados castellanos a Ceuta repartiéndose ropas entre el ejército en el otoño de 1642. De este modo, la ciudad, con unos 2.000 habitantes, contaba entre sus efectivos militares con 420 plazas de infantería distribuidas en dos compañías (la nueva y la vieja) y 130 de caballeria. En el plano naval, tenían tres barcos de largas dimensiones, un bergantín de 14 remos por banda y tres fragatas ${ }^{16}$.

En el plano económico, se mantuvo el régimen de exención de derechos en los mantenimientos, aplicado siempre por Portugal a Ceuta. Desde Castilla se procuraron los oportunos y difíciles asientos ya que la crisis bélica desencadenada por el movimiento secesionista portugués interrumpió los suministros desde la Baja Andalucía. En 1644 Ceuta que-

${ }^{14}$ Esaguy, J. de, Libro de los Veedores de Ceuta (Libro Grande de Sampayo) (15051670). Tánger 1939, pág. 189.

15 Ibidem., pág. 110.

16 Mascarenhas, J. de, op. cit., págs. 15-16. 
dó exenta del servicio de millones, medida que se prorrogaría en años sucesivos $(46,57,58,80,97,1700,1703)^{17}$.

A raíz de todos estos acontecimientos, las comunicaciones entre Ceuta y Portugal se interrumpieron y la dominación hispana sucedió a la portuguesa con análogos hechos de armas, parecidas represalias e igual resistencia a los ataques de los moros colindantes.

Desde Ceuta se solicitó del Rey la llegada de moneda acuñada particularmente para el pago de la guarnición, al dejar de recibirse moneda portuguesa debido a la actitud de los ceutíes. Se enviaron monedas con la efigie del monarca y cuyo valor era, respectivamente, de tres reales de vellón y las "carillas» de real y medio ${ }^{18}$.

Poco a poco, la vida en el presidio se fue normalizando y de ningún modo hubo un cambio sino que fue siempre una continuación de su historia inmediatamente anterior a los sucesos acaecidos en Portugal. Porque sería una falacia tratar de explicar la actitud de Ceuta por una causa única y específica, al contrario, fue el resultado de una trayectoria en la que se conjugaban múltiples causas cuya yuxtaposición sólo podía producir aquel efecto.

$\mathrm{Si}$ atendemos a motivos puramente políticos, entre 1640 y 1641 , Ceuta dejó de pertenecer a Portugal, de hecho, y no porque pasara automáticamente a la Corona de Castilla, sino porque decidió mantenerse fiel al soberano reinante independientemente de su origen portugués o castellano. Tras esta adhesión simplemente personal se produciría, en fase posterior, su paso a la órbita castellana.

Desde el punto de vista cultural, ya en aquella época resultaba notoria la semejanza de Ceuta con las poblaciones del litoral meridional español, seguramente debida al traslado de gentes, especialmente militares, desde Andalucía, que por su mayor proximidad acudieron de forma continua a la plaza ante el peligro de ataques fronterizos, desde la anexión de Portugal a España en 1580.

Sin duda, resulta también crucial a la hora de entender esta actitud incondicionalmente leal a su soberano, el tema económico. Hay que tener en cuenta que antes de la dominación lusitana, Ceuta era un núcleo clave en el comercio del Mediterráneo como una salida natural de pro-

iT. Luxan Melendez, S. de, «Política ceutí de Felipe IV (1641-1644)", Hispania, n, ${ }^{\circ} 132$, 1976, pág. 182.

${ }^{18}$ BNM, Mss. 9741, fol. $121 \mathrm{r}$. 
ductos y puerta de entrada de otros. Sin embargo, esta situación se transformó a raíz de la colonización portuguesa, ya que la plaza pasó a estar casi totalmente abastecida desde la Península debido, en primer lugar, a su nuevo status de presidio y en segundo lugar, al paso del tráfico marítimo del Mediterráneo al Atlántico. Efectivamente, «cuando la apertura del canal de Suez animó, de nuevo, el tráfico por el Estrecho de Gibraltar, se perdió una de las mejores ocasiones para transformar a Ceuta en una gran estación de servicio marítimo y cuando se logró, ya en nuestro siglo, otras ciudades vecinas habian mejorado sus puertos y lo que pudo ser una exclusiva se convirtió en una competencia» ${ }^{19}$.

$\mathrm{Su}$ alejamiento de los ejes comerciales nos lo demuestra el hecho de que casi todos los ciudadanos ceutíes dependian de la Real Hacienda, es decir, figuraban en las nóminas estatales: empleados públicos, soldados, beneficiarios de «tensas» y «moradías» ${ }^{20}$, viudas y huérfanos de caídos en el campo de batalla,... De ahí la vinculación de la economía ceutí con el sur peninsular y el norte africano, antes y después del movimiento secesionista portugués. Así, en una carta de Felipe IV al marqués de Flores Dávila, gobernador de Orán, fechada el 28 de marzo de 1633, puede leerse:

«Habiéndose visto lo que habéis escrito en carta de 26 de enero pasado sobre que en las ocasiones de necesidad socorran a esas plazas las ciudades de Murcia y Cartagena, en la forma que lo han acostumbrado, lo he mandado escribir así al marqués de los Vélez, mi adelantado y Capitán Mayor del Reino de Murcia y a las mismas ciudades con quien os corresponderéis en las ocasiones que llegare el caso de ser necesaria esta asistencia» ${ }^{21}$.

Ante las continuas interrupciones de los envíos, el sistema de asientos era el encargado de garantizar la llegada de bastimentos y dinero a Ceuta. De todos modos, las entradas de trigo en Ceuta se realizaban con una enorme irregularidad y el cumplimiento de las cláusulas de los asientos se llevaba a cabo con gran lentitud. Ya en 1647, Manuel y Bartolomé

19 Gordillo Osuna, M., op. cit., pág. 268.

20 Las tensas eran pensiones vitalicias concedidas con cargo a la Real Hacienda, como premio por servicios destacados a la Corona o al bien común que podían transmitirse por herencia. Sin embargo, las moradias eran una especie de subsidio unido, en muchos casos, a la concesión de una hildaguía o de un hábito de Orden Militar y no podían heredarse.

21 BRaH, Colección Salazar y Castro, K-16 (9/641), fol. 62. . 
Montesinos aparecen como abastecedores de Ceuta, cargo en el que se mantendrían hasta $1666^{22}$.

En 1648, en plena oleada de peste en la Península y en el Norte de África, Ceuta "siéndole precisos los bastimentos, comerciaba con los Puertos de Andalucía» ${ }^{23}$. Esta situación se prolongó de modo que a fines del siglo XVIII, Málaga se había convertido en el centro gestor a través del cual los Cinco Gremios Mayores de Madrid llevaban a cabo el aprovisionamiento de viveres de los presidios norteafricanos.

Sin embargo, no era el Sur peninsular el único foco abastecedor de Ceuta ya que intermitentemente y si las buenas relaciones así lo aconsejaban, se establecía un rico y frecuente comercio entre los ceutíes y los moros. Por parte mora se traficaba con cera, pieles, alfombras, tapetes, tabaco, ámbar, dátiles, lencería, lino, aves, manteca, miel, almendras, leche, queso. Los ceutíes, por su parte, negociaban con pedrería, grana, añil, paños de Segovia y otros géneros; nunca con plata, oro ni artículos que pudieran servir para la guerra. Según Correa da Franca, los moros, a su vez, rehusaban concurrir con granos, caballos, vacas y carneros, salvo en raras ocasiones y con pretexto de regalo ${ }^{24}$. Sin embargo, y debido a las malas cosechas ${ }^{25}$, en muchas ocasiones se acudió en busca de grano al Norte de África para abastecer tanto a los presidios como a la Península. Así, en agosto de 1635 se solicitaba el envío de trigo y cebada desde el Norte de África hasta Barcelona para abastecer al Ejército por resultar más fácil su transporte desde alí que desde Aragón y por ser escasa la cosecha en Castilla ${ }^{26}$.

De nuevo, en septiembre de 1636 se solicitó de Orán la provisión de trigo para la Armada debido a la escasa cosecha recogida en Andalucía. El Gobernador de Orán debía comprarlo a los moros y enviarlo a Cádiz ${ }^{27}$. Estas peticiones se sucedían en períodos de malas cosechas en Castilla y Andalucía.

22 LuXÁN MelénDEZ, S. de, “Contribución al estudio...”, op. cit., pág. 331.

${ }^{23}$ BNM, Mss. 9741 , fol. $128 \mathrm{r}$.

24 Ibidem., fol. $138 \mathrm{r}$.

${ }^{25}$ Ver ANES, G., Las crisis agrarias en la España Moderna. Madrid 1970; id., «La depresión agraria durante el siglo XVII en Castilla», Homenaje a Julio Caro Baroja, 1978, págs. 83-100.

${ }^{26}$ BRAH, Colección Salazar y Castro, K-16 (9/641), fol. 108. Correspondencia entre Felipe IV y el marqués de Flores Dávila, gobernador de Orán, en la década inmediatamente anterior a la revolución portuguesa.

${ }^{27}$ Ibidem., fol. 132. 
Así pues, por motivos políticos, económicos, culturales y militares, la asimilación de Ceuta a España fue completa desde 1580. La sociedad ceutí, en el momento de la secesión portuguesa, estaba plenamente identificada con la raíz hispánica y por lo tanto, muy alejada de los anhelos nacionalistas que imperaban en la Metrópoli. Así lo entendieron la mayor parte de sus dirigentes tanto políticos como eclesiásticos ${ }^{28}$.

Con el paso del tiempo fue aumentando el valor estratégico y militar de Ceuta, sobre todo, a partir de la primavera de 1661 con motivo de concertarse el matrimonio entre Carlos II de Inglaterra, el que viviera en el exilio de Brujas, al amparo del apoyo prestado por Felipe IV ${ }^{29}$ y Catalina de Braganza, hermana de Alfonso VI de Portugal, el cual llevaba aparejada una gruesa dote que incluía la cesión de Tánger a los ingleses. De ese modo, Portugal abandonaba el último presidio que le quedaba en África. Precisamente, el Gobernador de Ceuta recibió la orden del Consejo de Portugal encaminada a dar publicidad en Tánger a la noticia de su entrega a Inglaterra, en dote, para producir el movimiento adverso de sus naturales, lo cual favorecía a la monarquía hispánica ${ }^{30}$.

Con el Tratado de Paz de Lisboa, firmado en 1668, Portugal reconocía y respetaba definitivamente la realidad de Ceuta a la que se había llegado por decisión voluntaria y comunitaria de la plaza:

«En la paz que he ajustado con Portugal, he dispuesto quedéis agregados a la Corona de Castilla, deseando manifestar en esto el amor particular que os tengo, correspondiente al que con tanta fineza habéis mostrado en todas ocasiones al servicio del Rey mi hijo, to cual tendré siempre presente para favoreceros y honraros en las que se ofreciesen de vuestra conveniencia y mayor satisfacción de vuestros naturales, en cuya consciencia he mandado se os guarden las leyes y costumbres

${ }^{28}$ El Cabildo de Ceuta se limitó a solicitar ayuda económica de la Península habida cuenta de las pérdidas sufridas con motivo de la sublevación de Portugal, ayuda que Felipe IV se comprometió a otorgar si bien, su promesa se encontraba aún incumplida en 1646: “Por las noticias que la Cámara tiene de la necesidad que pasa este Cabildo después de la sublevación de Portugal y por lo que conviene alentarle por la consecuencia de los demás y su mucha fidelidad, es de parecer la Cámara que siendo $\mathrm{V}$. Md. servido, puede mandar se le cumpla con efecto la merced que V. Md. le tiene hecha...” (AHN, Consejos, leg. 4430, exp. 123. Comunicación de la Cámara de Castilla al Rey de 7 de diciembre de 1646).

${ }^{29}$ Ver CASTILLA Soto, J., "Las relaciones entre Felipe IV y Carlos II de Inglaterra durante el protectorado de Cromwell (1656-1659), Espacio, Tiempo y Forma, serie IV, núm. 2, 1989 , págs. $111-123$.

${ }^{30}$ BNM, Mss. 2388, fol. 19. Consulta del Consejo de Portugal al Consejo de Estado de 25 de junio de 1661 . 
con que os habéis gobernado hasta ahora y tendré particular atención a vuestra conservación, para lo cual se continuará el asiento de manera que no experimentéis ninguna falta y espero que vos continuaréis los afectos de vuestro celo con aquel afecto que hasta aquí, de su Magestad» ${ }^{31}$.

${ }^{31}$ Mascarenhas, J. de, op. cit., pág. 296. Carta de doña Mariana de Austria a la ciudad de Ceuta de 19 de mayo de 1668, citada por el director de la publicación. Alfonso de Dornellas. 